\title{
Anatomical and Functional Evaluation of Conventional vs Inferior Endoscopic Dacryocystorhinostomy in Study Cases of Idiopathic Chronic Dacryocystitis
}

\author{
${ }^{1}$ Kuldeep Thakur, ${ }^{2}$ Aditya Kashyap, ${ }^{3}$ Satisg Negi, ${ }^{4}$ Prem L Chauhan
}

\begin{abstract}
Objective: To compare the results of conventional nasal endoscopic dacryocystorhinostomy (DCR) and inferior nasal endoscopic DCR in Study cases of idiopathic chronic dacryocystitis.

Materials and methods: Forty patients diagnosed with idiopathic chronic dacryocystitis were divided into two groups alternately. After relevant investigations, they were subjected for endoscopic DCR by two techniques. Twenty patients underwent conventional endoscopic DCR and 20 underwent inferior endoscopic DCR under transoral pterygopalatine block and topical lignocaine (4\%) with adrenaline 1:2,000. After 3 months of follow-up in the outpatient department, nasal endoscopy along with fluorescein dye disappearance test (FDDT) at 10 minutes was done.
\end{abstract}

Results: Ninety-five percent (19/20) of patients undergoing conventional endoscopic DCR and 90\% (18/20) of patients undergoing inferior endoscopic DCR were found to have patent anatomical fistula. On FDDT, nasal endoscopy after 10 minutes revealed $84 \%(16 / 19)$ in group I and $94.4 \%(17 / 18)$ in group II with fluorescein in nasal cavity.

Conclusion: Present study concludes the importance of bony, tendinous, and muscular support of lacrimal sac in physiological lacrimal pump functioning and advantage of relatively new technique of inferior endoscopic DCR. Inferior endoscopic DCR is associated with less operative time as well as less local complications.

Keywords: Chronic dacryocystitis, Dacryocystorhinostomy, Nasolacrimal duct obstruction.

\footnotetext{
${ }^{1-4}$ Consultant

${ }^{1}$ Department of ENT, Head and Neck Surgery, Mahatma Gandhi Medical Services Complex Khaneri, Shimla, Himachal Pradesh India

${ }^{2}$ Department of Ophthalmology, Mahatma Gandhi Medical Services Complex Khaneri, Shimla, Himachal Pradesh, India

${ }^{3}$ Department of Anaesthesia and ICU, Mahatma Gandhi Medical Services Complex Khaneri, Shimla, Himachal Pradesh, India

${ }^{4}$ Department of Community Medicine, Mahatma Gandhi Medical Services Complex Khaneri, Shimla, Himachal Pradesh, India

Corresponding Author: Kuldeep Thakur, Consultant Department of ENT, Head and Neck Surgery Mahatma Gandhi Medical Services Complex Khaneri, Shimla, Himachal Pradesh India, Phone: +9101782233970, e-mail: drkuldeep70@gmail. com
}

How to cite this article: Thakur K, Kashyap A, Negi S, Chauhan PL. Anatomical and Functional Evaluation of Conventional vs Inferior Endoscopic Dacryocystorhinostomy in Study Cases of Idiopathic Chronic Dacryocystitis. Clin Rhinol An Int J 2017;10(2):86-90.

\section{Source of support: Nil}

Conflict of interest: None

\section{INTRODUCTION}

Dacryocystorhinostomy (DCR) through transnasal route was first described by Caldwell ${ }^{1}$ in 1893 and was further modified by West and Mosher. Due to poor visualization of lacrimal sac, this procedure did not gain popularity until the introduction of new popular endoscopic endonasal DCR in 1989 by McDonogh and Meiring. ${ }^{2}$ The above authors (McDonogh and Meiring) used rigid nasal endoscopes which provide excellent visualization of endonasal anatomy and also it is a prerequisite for successful outcome of endoscopic DCR. Chronic dacryocystitis is a chronic low-grade infection of lacrimal sac ultimately leading to nasolacrimal duct obstruction (NLDO) presenting as watering or purulent discharge from eyes and disturbance in vision due to presence of continuous tear film which cannot be cleared. Dacryocystorhinostomy is a surgical procedure used to marsupialize the lacrimal sac into the nasal cavity. Dacryocystorhinostomy is used to drain sac in cases with intrasaccular or postsaccular obstruction. Most common indication of DCR in routine practice is NLDO. Dacryocystorhinostomy can be done through either external or endonasal route. Endonasal route is more favorable because it is less traumatic with no facial scar, no angular facial vessel trauma, and does not involve disruption of medial palpebral ligament. ${ }^{3}$ Endonasal DCR is associated with high efficacy, relative ease in operating revision cases and less operative complications. Success rate of endonasal endoscopic DCR varies from 82 to $95 \% .{ }^{4}$ Endoscopic DCR also identifies the intranasal pathologies responsible for the failure of DCR, such as sinusitis, adhesions, and obstructing middle turbinate. Infection from the inflamed sac may spread to orbit causing orbital cellulitis, nonhealing ulcer on cornea, or even meningitis, thus requiring early and effective treatment. ${ }^{5}$ 
Traditional teaching involves marsupialization of whole sac to create a large opening; however, Linberg et $\mathrm{al}^{6}$ stated that size of the stoma created during endonasal DCR bears a little relationship with the final fistula size in nasal mucosa.

Yung and Hardmen Lea ${ }^{7}$ observed that conventional DCR involves extensive removal of bone of lacrimal fossa and destruction of lacrimal sac leading to lacrimal pump failure.

The present study focuses on the anatomical patency, lacrimal pump functioning, and the role of conservative removal of lacrimal sac walls in conventional and inferior endoscopic endonasal DCR.

\section{MATERIALS AND METHODS}

This is a prospective study conducted in a multispecialty hospital in the sub-Himalayan region. The study was carried on 40 patients, alternately placed in two groups, of both sexes in the age group of 27 to 75 years over a period of 20 months including data collection, data organization, and interpretation.

\section{Inclusion Criteria}

Idiopathic chronic dacryocystitis.

\section{Exclusion Criteria}

Pathologies related to eyelids, canalicular blockade, lacrimal sac tumor, acute dacryocystitis, chronic rhinosinusitis, and nasal polyposis.

Patients were allocated into groups after fulfilling the inclusion and exclusion criteria:

- Group I: Patients undergoing conventional endoscopic DCR.

- Group II: Patients undergoing inferior endoscopic DCR.

Patients included in the study were subjected to thorough whole body examination, regurgitation test, lacrimal saline syringing, and nasal endoscopy under topical lignocaine $4 \%$. Laboratory tests including routine blood tests, chest $\mathrm{X}$-ray, and electrocardiogram were performed and sent for preanesthesia examination. After clearance from anesthetist, fresh informed consent was obtained from the patients and subjected for surgery.

\section{Procedure}

All surgeries were performed under transoral pterygopalatine block, topical lignocaine $4 \%$ with adrenaline $(1: 2,000)$, and diluted IV pentazocine. In transoral pterygopalatine block, $2 \mathrm{~mL}$ of $2 \%$ lignocaine with 1:80,000 adrenaline was injected through greater palatine foramen with $2 \mathrm{cc}$ syringe after bending needle at $45^{\circ}$ angle, $2 \mathrm{~cm}$ from the tip of needle. Septum was infiltrated with $2 \%$ lignocaine with 1:80,000 adrenaline when endoscopic septoplasty was required. Endoscopic septoplasty was performed by a traditional method. After septoplasty, when required, endoscopic DCR was performed by two methods alternately.

\section{Superior Dacryocystorhinostomy}

- Horizontal incision given 6 to $8 \mathrm{~mm}$ above axilla of middle turbinate extending 5 to $6 \mathrm{~mm}$ anterior to axilla. Another horizontal incision was given just above the insertion of inferior turbinate parallel to superior horizontal incision.

- Two vertical incisions were given, one along maxillary line and another connecting anterior ends of two horizontal incisions.

- Mucosal flap was elevated and removed along with lacrimal bone with Freer's elevator.

- Ascending process of maxilla was removed with $2 \mathrm{~mm}$ $45^{\circ}$ Kerrison Rongeur inferiorly and $2 \mathrm{~mm}$ diamond burr superiorly till the whole lacrimal sac was delineated.

- Thin periosteal covering overlying the sac was removed with sickle knife.

- Sac is marsupialized widely by vertical incision with no. 11 blade, anterior and posterior flaps created with sickle knife and endoscopic scissor.

- Both ends of anterior and posterior flaps are approximated with nasal mucosa overlying ascending process and uncinate bone respectively.

- Marsupialized sac and nasal mucosa are impregnated with fucidic acid ointment.

- No nasal pack is kept except in those patients who underwent endoscopic septoplasty.

\section{Inferior Dacryocystorhinostomy}

- Superior horizontal incision was given at the level of insertion of middle turbinate, 6 to $8 \mathrm{~mm}$ anteriorly.

- Inferior horizontal incision was given parallel to superior incision just above the insertion of inferior turbinate.

- Two vertical incisions were given, one along maxillary line and another connecting anterior ends of two horizontal incisions.

- Mucosal flap was elevated and removed along with lacrimal bone.

- Ascending process of maxilla was removed with $2 \mathrm{~mm}$ $45^{\circ}$ Kerrison Rongeur inferiorly overlying lower half of lacrimal sac. Bone overlying superior half of sac was left in situ.

- Thin periosteal covering overlying lower half of sac was removed with sickle knife. 
- Lower half of sac and part of nasolacrimal duct are marsupialized by vertical incision with no. 11 blade, anterior and posterior flaps are created with sickle knife and endoscopic scissor.

- Both ends of anterior and posterior flaps are approximated with nasal mucosa overlying ascending process and uncinate bone respectively.

- Marsupialized sac and nasal mucosa are impregnated with fusidic acid ointment.

Lacrimal syringing was done on first postoperative day to remove blood clots and residual ointment. Patients were instructed saline nasal wash regularly along with moxifloxacin with dexamethasone eye drops for 1 month. Postoperative visits were arranged at 1st, 3rd, 8th, and 15 th weeks respectively. In each visit, lacrimal syringing and nasal endoscopy were done in order to inspect and remove crusts and cauterize any granulation tissue if present. At completion of 3 months, patients' eye symptoms were asked along with nasal endoscopy and fluorescein dye disappearance test (FDDT). Fluorescein dye disappearance test was done in cases with visible lacrimal fistula on nasal endoscopy by instilling two drop of $2 \%$ sodium flouroscein into each lower conjunctival cul-desac. Postoperative results at 3 months in both the groups were compared by using three parameters, discharge (watery/purulent)(W/P) from eyes, anatomical patent lacrimal fistula, and FDDT.

\section{RESULTS}

Most of the patients in our study were in the age group of 30 to 50 years, the youngest being 27 years and oldest being 75 years (Table 1 ). Three patients were male and 37 patients were female. Twenty-four patients were having involvement on left side whereas 16 patients had right side involvement. Endoscopic septoplasty was done in 4 and 1 in groups I and II respectively (Table 2$)$. Five $(4 \mathrm{~W}+1 \mathrm{P})$ patients in group I and $3(1 \mathrm{~W}+2 \mathrm{P})$ patients in group II were having discharge from eye postoperatively. Ninetyfive percent $(19 / 20)$ of patients in group I were found to
Table 1: Age distribution

\begin{tabular}{llll}
\hline Age (years) & Group I & Group II & Total \\
\hline $20-30$ & 1 & 0 & 1 \\
$31-40$ & 7 & 4 & 11 \\
$41-50$ & 4 & 5 & 9 \\
$51-60$ & 6 & 9 & 15 \\
$61-70$ & 2 & 1 & 3 \\
$71-80$ & 0 & 1 & 1 \\
\hline Total & 20 & 20 & 40 \\
\hline
\end{tabular}

Table 2: Gender, side, DNS, and endoscopic septoplasty distribution

\begin{tabular}{|c|c|c|c|c|c|c|c|}
\hline \multirow[b]{2}{*}{ Groups } & \multicolumn{2}{|c|}{ Sex } & \multicolumn{2}{|c|}{ Side incidences } & \multicolumn{2}{|c|}{ DNS } & \multirow{2}{*}{$\begin{array}{l}\text { Endoscopic } \\
\text { septoplasty }\end{array}$} \\
\hline & $M A$ & $F A$ & $R t$ & $L t$ & $R t$ & $L t$ & \\
\hline 1 & 1 & 19 & 10 & 10 & 7 & 8 & 4 \\
\hline II & 2 & 18 & 6 & 14 & 5 & 11 & 1 \\
\hline
\end{tabular}

DNS: Deviated nasal septum; MA: Male; FA: Female; Lt: Left; Rt: Right

have patent anatomical lacrimal fistula whereas $90 \%$ $(18 / 20)$ had patent anatomical lacrimal fistula in group II. Eighty-four percent (16/19 patients) in group I and 94.4\% (17/18 patients) in group II were having positive FDDT at 10 minutes. Lacrimal pump failure was found in 16 and $5.6 \%$ in groups I and II respectively (Table 3 ). Ninety-five percent of patients in group I and $90 \%$ patients in group II were satisfied from the surgery. Postoperative complications were insignificant, five patients in group I and two patients in group II reported minor postoperative bleeding which were managed conservatively. Three patients in group I and one patient in group II reported minor swelling in medial canthal region (Table 4). Operating time in inferior endoscopic DCR was found to be less (35-40 minutes) as compared with conventional endoscopic DCR (about 1 hour).

\section{DISCUSSION}

Dacryocystitis is the most common infection of nasolacrimal apparatus. This apparatus acts as an excretory system, draining tears from the eye into the nasal cavity. Obstruction at the level of nasolacrimal duct leads to

Table 3: Results: Subjective (discharge from eye), objective in terms of nasal endoscopy, FDDT

\begin{tabular}{lllllll}
\hline \multirow{2}{*}{ Groups } & \multicolumn{2}{l}{ Eye discharge $($ Post-op) } & & $\begin{array}{l}\text { Lacrimal fistula on nasal } \\
\text { endoscopy (Post-op) }\end{array}$ & $\begin{array}{l}\text { Positive FDDT (post-op) } \\
\text { at 10 minutes }\end{array}$ & $\begin{array}{l}\text { Physiological } \\
\text { pump failure }\end{array}$ \\
\cline { 2 - 3 } I Watery & Purulent & & $19 / 20(95 \%)$ & $16 / 19(84 \%)$ & $3 / 19(16 \%)$ \\
II & $4 / 20(20 \%)$ & $1 / 20(5 \%)$ & & $18 / 20(90 \%)$ & $17 / 18(94.4 \%)$ & $1 / 18(5.6 \%)$ \\
\hline
\end{tabular}

Table 4: Postoperative complications

\begin{tabular}{lllll}
\hline Groups & $\begin{array}{l}\text { Post-op hemorrhage } \\
\text { (minor) }\end{array}$ & $\begin{array}{l}\text { Minor swelling in } \\
\text { medial canthus }\end{array}$ & $\begin{array}{l}\text { Synechia in } \\
\text { nasal cavity }\end{array}$ & $\begin{array}{l}\text { Symptomatic failure } \\
\text { of surgery }(W+P)\end{array}$ \\
\hline I & 5 & 3 & 0 & $5(4+1)$ \\
II & 2 & 1 & 2 & $3(1+2)$ \\
\hline Total & 7 & 4 & 2 & $8(5+3)$ \\
\hline
\end{tabular}


stasis of mucoid secretions, tears, and desquamated cells, which act as a fertile environment for bacterial infection. Nasolacrimal duct obstruction can occur due to a variety of causes, though idiopathic obstruction is most common. Less common causes are infectious, posttraumatic, and secondary to neoplastic lesions. Nasolacrimal duct obstruction can occur in any age group, although the precise prevalence of the disease is still not known. Congenital NLDO occurs in 3 to $6 \%$ of full-term infants mostly due to either blockage due to epithelial debris or due to imperforate membrane secondary to incomplete canalization of the embryonic duct. ${ }^{8}$ Acquired NLDO occurs mainly in middle-aged or older patients with a 3:1 female preponderance, and left lacrimal sac involvement is more than right side. ${ }^{9}$

Lacrimal clearance depends on many factors including capillary attraction forces, gravity, evaporation, absorption from conjunctival sac, and lacrimal pump. The exact mechanism of lacrimal pump is still not known; however, contraction of Horner's muscle which is a deep part of orbicularis muscle is associated with expansion of lacrimal sac and creation of negative pressure leading to tears suction. Other theories suggest that opening of eyelids causes elastic expansion of lacrimal papillae, which sucks tears and subsequent contraction of orbicularis oculi muscle creates a positive pressure gradient that drives tears into the nasolacrimal duct. Irrespective of the exact mechanism, contraction of orbicularis oculi muscle, as well as an adequate elastic tension of the eyelids is considered critical in maintaining the pump mechanism..$^{10}$

The traditional treatment for NLDO was external DCR mostly performed by ophthalmologists. With the technological innovations, batter visualization and less invasive techniques of opening lacrimal system have been developed, resulting in improved results and less complications. Currently, endoscopic DCR is the gold standard technique in management of nasolacrimal ductal and sac obstruction. The aim of DCR surgery is to provide an alternate pathway for tear drainage into the nasal cavity. The techniques of endoscopic DCR vary from author to author with either cold steal method or power DCR or laser method.

The success rate of endoscopic DCR varies from 82 to $95 \%$ though it is not easy to compare results because different studies have different parameters for the measurement of success or failure of surgery. Freedom from epiphora 3 months following surgery is the marker of satisfactory procedure as described by the Royal College of Ophthalmologists in 1999. ${ }^{11}$

Conventional endoscopic DCR involves wide exposure of the lacrimal sac and marsupialization along with primary mucosal anastomosis, yielding $89 \%$ success rate. ${ }^{4,12}$ Although still controversial, small osteotomy size in some studies has been found a common cause of DCR failure. ${ }^{6,13}$ In primary DCR cases, 90 to $95 \%$ of success rate was found in relieving anatomical obstruction, whereas this rate steps down to 80 to $85 \%$ in terms of functional outcome. The success rate further reduces in revision cases. ${ }^{14}$ In the present study, $95 \%$ of patients undergoing conventional endoscopic DCR were found to have parent anatomical lacrimal fistula, among them $16 \%$ of patients were having physiological lacrimal pump failure. In other groups where patients underwent inferior endoscopic DCR, anatomical patent fistula was found in $90 \%$ patients; however, physiological lacrimal pump failure was found in only $5.6 \%$ patients. Hardmen Lea ${ }^{7}$ described a new technique of DCR; inferior endoscopic DCR done on consecutive 81 patients revealed success rate of over $90 \%$, which was maintained over a period of time. They observed a wide lacrimal window postoperatively with preserved lacrimal pump function. ${ }^{7}$ In this technique, the superior portion of the lacrimal sac is preserved along with the tendinous and bony supporting structure, thereby preserving physiological lacrimal pump. Similar results were found in our study revealing improved lacrimal pump function as compared with conventional endoscopic DCR.

Wormald ${ }^{4}$ introduced relatively a new technique of power endoscopic DCR with full exposure of sac and primary mucosal anastomosis yielding success rate of $95.7 \%$.

Intraoperative use of Mitomycin- $C$ has been found very effective in some studies as it prevents reclosure of stoma; however, Zilelioglu et $\mathrm{al}^{15,16}$ declined the role of Mitomycin-C in DCR.

Role of silicon tubes is still controversial in primary DCR; however, few authors advocate its role in revision DCR, canalicular stenosis, and narrow nasal cavities. ${ }^{6,13}$

We performed all our case under local anesthesia and pterygopalatine block with few minor intraoperative and postoperative complications. Howden et $\mathrm{al}^{17}$ reported no anesthetic complications in 26 patients who underwent endoscopic DCR under local anesthesia. Pterygopalatine block was found to be associated with less intraoperative bleeding and less operative time. Few patients in the immediate postoperative period reported scanty postnasal bleeding, which was managed conservatively with propped up position and IV tranexamic acid injection. Intranasal fusidic acid ointment was applied topically in operative site following surgery, and none of the patients were given nasal packing except cases where septoplasty was done.

Saline nasal wash was found to be very effective in rapid recovery postoperatively as it helps in removal of 
blood clots and crusts from nasal cavity and restores the cilliary function of nasal mucosa. Postoperative care is found to be very important in terms of successful outcome. Few cases of granulation tissue on anterior lip of nasolacrimal fistula were found in postoperative period in our study, which subsequently resolved after prescription of antibiotic with steroid eye drops and topical trichloroacetic acid cautry postoperatively. Postoperative complications in the form of local swelling and minor postnasal bleeding were found less in inferior endoscopic DCR cases as compared with conventional nasal endoscopic DCR cases.

\section{CONCLUSION}

Conventional endoscopic DCR was found to be very effective in chronic dacryocystitis in terms of patent anatomical lacrimal fistula; however, relatively new technique of endoscopic DCR, inferior endoscopic DCR was found to preserve physiological lacrimal pump functioning. Moreover, inferior endoscopic nasal DCR was found to be associated with less operative time (35-40 minutes) and local complications as compared with conventional endoscopic nasal DCR (about 1 hour).

\section{REFERENCES}

1. Caldwell G. Two new operations for obstruction of the nasal duct, with preservation of the canaliculi, and with an incidental description of a new lachrymal probe. Am J Ophtalmol 1893;10:189-193.

2. McDonogh M, Meiring JH. Endoscopic transnasal dacryocystorhinostomy. J Laryngol Otol 1989 Jun;103(6):585-587.

3. Weidenbecher M, Hosemann W, Buhr W. Endoscopic endonasal dacryocystorhinostomy: results in 56 patients. Ann Otol Rhinol Laryngol 1994 May;103(5 Pt 1):363-367.
4. Wormald PJ. Powered endoscopic dacryocystorhinostomy. Laryngoscope 2002 Jan;112(1):69-72.

5. Woog JJ, Kennedy RH, Custer PL, Kaltreider SA, Meyer DR, Camara JG. Endonasal dacryocystorhinostomy: a report by the American Academy of Ophthalmology. Ophthalmology 2001 Dec;108(12):2369-2377.

6. Linberg JV, Anderson RL, Bumsted RM, Barreras R. Study of intranasal ostium external dacryocystorhinostomy. Arch Ophthalmol 1982 Nov;100(11):1758-1762.

7. Yung MW, Hardmen Lea S. Endoscopic inferior dacryocystorhinostomy. Clin Otolaryngol Allied Sci 1998 Apr;23(2):152-157.

8. Kushner BJ. Congenital nasolacrimal system obstruction. Arch Ophthalmol 1982 Apr;100(4):597-600.

9. Linberg, JV. Disorders of the lower excretory system. In: Milder, B; Weil, BA, editors. The Lacrimal System. New York: Appleton-Century-Crofts; 1983. p. 1-134.

10. Detorakis ET, Zissimopoulos A, Ioannakis K, Kozobolis VP. Lacrimal outflow mechanisms and the role of scintigraphy: current trends. World J Nucl Med 2014 Jan-Apr;13(1):16-21.

11. Royal College of Ophthalmologists. Guideline for clinical governance in ophthalmology. London: RCO; April 1999.

12. Tsirbas A, Wormald PJ. Endonasal dacryocystorhinostomy with mucosal flaps. Am J Ophthalmol 2003 Jan;135:76-83.

13. Ben Simon GJ, Brown C, McNab AA. Larger osteotomies result in larger ostia in external dacryocystorhinostomies. Arch Facial Plast Surg 2012 Mar-Apr;14(2):127-131.

14. Tsirbas A, Wormald PJ. Mechanical endonasal dacryocystorhinostomy with mucosal flaps. Otolaryngol Clin North Am 2006 Oct;39(5):1019-1036.

15. Camara JG, Bengzon AU, Henson RD. The safety and efficacy of mitomycin $\mathrm{C}$ in endonasal endoscopic laser assisted dacryocystorhinostomy. Ophthal Plast Reconstr Surg 2000 Mar;16(2):114-118.

16. Zilelioglu G, Ugurbas SH, Anadolu Y, Akiner M, Akturk T. Adjunctive use of mitomycin $\mathrm{C}$ on endoscopic lacrimal surgery. Br J Ophthalmol 1998 Jan;82(1):63-66.

17. Howden J, McCluskey P, O'Sullivan G, Ghabrial R. Assisted local anaesthesia for endoscopic dacryocystorhinostomy. Clin Exp Ophthalmol 2007 Apr;35(3):256-261. 